\title{
Front Matter: Volume 8857
}

, "Front Matter: Volume 8857," Proc. SPIE 8857, Signal and Data Processing of Small Targets 2013, 885701 (4 October 2013); doi: 10.1117/12.2046046

SPIE Event: SPIE Optical Engineering + Applications, 2013, San Diego, California, SPIE. United States 


\section{PROCEEDINGS OF SPIE}

\section{Signal and Data Processing of Small Targets 2013}

Oliver E. Drummond

Richard D. Teichgraeber

Editors

28-29 August 2013

San Diego, California, United States

Sponsored and Published by

SPIE 
The papers included in this volume were part of the technical conference cited on the cover and title page. Papers were selected and subject to review by the editors and conference program committee. Some conference presentations may not be available for publication. The papers published in these proceedings reflect the work and thoughts of the authors and are published herein as submitted. The publisher is not responsible for the validity of the information or for any outcomes resulting from reliance thereon.

Please use the following format to cite material from this book:

Author(s), "Title of Paper," in Signal and Data Processing of Small Targets 2013, edited by Oliver E. Drummond, Richard D. Teichgraeber, Proceedings of SPIE Vol. 8857 (SPIE, Bellingham, WA, 2013) Article CID Number.

ISSN: 0277-786X

ISBN: 9780819497079

Published by

SPIE

P.O. Box 10, Bellingham, Washington 98227-0010 USA

Telephone +1 3606763290 (Pacific Time) · Fax +1 3606471445

SPIE.org

Copyright (C) 2013, Society of Photo-Optical Instrumentation Engineers.

Copying of material in this book for internal or personal use, or for the internal or personal use of specific clients, beyond the fair use provisions granted by the U.S. Copyright Law is authorized by SPIE subject to payment of copying fees. The Transactional Reporting Service base fee for this volume is $\$ 18.00$ per article (or portion thereof), which should be paid directly to the Copyright Clearance Center (CCC), 222 Rosewood Drive, Danvers, MA 01923. Payment may also be made electronically through CCC Online at copyright.com. Other copying for republication, resale, advertising or promotion, or any form of systematic or multiple reproduction of any material in this book is prohibited except with permission in writing from the publisher. The CCC fee code is 0277-786X/13/\$18.00.

Printed in the United States of America.

Publication of record for individual papers is online in the SPIE Digital Library.

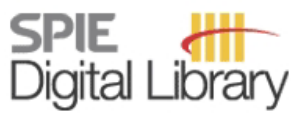

SPIEDigitalLibrary.org

Paper Numbering: Proceedings of SPIE follow an e-First publication model, with papers published first online and then in print and on CD-ROM. Papers are published as they are submitted and meet publication criteria. A unique, consistent, permanent citation identifier (CID) number is assigned to each article at the time of the first publication. Utilization of CIDs allows articles to be fully citable as soon as they are published online, and connects the same identifier to all online, print, and electronic versions of the publication. SPIE uses a six-digit CID article numbering system in which:

- The first four digits correspond to the SPIE volume number.

- The last two digits indicate publication order within the volume using a Base 36 numbering

system employing both numerals and letters. These two-number sets start with 00, 01, 02, 03, 04, $05,06,07,08,09,0 A, 0 B \ldots 0 Z$, followed by 10-1Z, 20-2Z, etc.

The CID Number appears on each page of the manuscript. The complete citation is used on the first page, and an abbreviated version on subsequent pages. Numbers in the index correspond to the last two digits of the six-digit CID Number. 


\title{
Contents
}

\author{
$\checkmark$ Conference Committee \\ vii Introduction \\ xi Signal and Data Processing Workshop
}

SIGNAL PROCESSING

885703 Small object detection via fast discrete Curvelet transform [8857-1]

H. A. Valdez, California State Univ., Long Beach (United States); T. T. Lu, T.-H. Chao, Jet

Propulsion Lab. (United States)

885705 An examination of the application of space time adaptive processing for the detection of maritime surface targets from high altitude airborne platforms [8857-3]

M. McDonald, Defence Research and Development Canada (Canada); D. Cerutti-Maori, Fraunhofer Institute for High Frequency Physics and Radar Techniques (Germany)

885707 Improving variance estimation ratio score calculation for slow moving point targets detection in infrared imagery sequences [8857-5]

R. Huber-Shalem, O. Hadar, S. R. Rotman, M. Huber-Lerner, S. Evstigneev, Ben Gurion Univ. of the Negev (Israel)

885708 Identification of human motion signature using airborne radar data [8857-6] M. McDonald, A. Damini, Defence Research and Development Canada (Canada)

\section{TARGET TRACKING}

885709 Particle filter tracking for the banana problem [8857-9]

K. Romeo, P. Willett, Y. Bar-Shalom, Univ. of Connecticut (United States)

8857 OA Particle flow with non-zero diffusion for nonlinear filters, Bayesian decisions and transport [8857-10]

F. Daum, J. Huang, Raytheon Co. (United States)

8857 OC Estimability of thrusting trajectories in 3-D from a single passive sensor with unknown launch point [8857-12]

T. Yuan, Y. Bar-Shalom, P. Willett, R. Ben-Dov, S. Pollak, Univ. of Connecticut (United States)

8857 OD A minimalist approach to bias estimation for passive sensor measurements with targets of opportunity [8857-13]

D. Belfadel, R. W. Osborne III, Y. Bar-Shalom, Univ. of Connecticut (United States)

$8857 \mathrm{OE}$ On covariance structure in noisy, big data [8857-25]

R. C. Paffenroth, R. Nong, P. C. Du Toit, Numerica Corp. (United States) 
$8857 \mathrm{OF}$ Detection of unusual trajectories using multi-objective evolutionary algorithms and rough sets [8857-15]

T. G. Smolinski, T. Newell, S. McDaniel, D. Pokrajac, Delaware State Univ. (United States)

8857 OG Effect of sensor pixel size on tracking [8857-16]

R. W. Osborne III, X. Zhang, P. Willett, Y. Bar-Shalom, Univ. of Connecticut (United States)

8857 Ol Target track extraction in high false density environments using multiple hypothetical frame selection MLPDA [8857-18]

M. Mori, T. Matsuzaki, H. Kameda, T. Umezawa, Mitsubishi Electric Corp. (Japan)

8857 0J Directional sensor control for maximizing information gain [8857-19]

S. Ragi, Colorado State Univ. (United States); H. D. Mittelmann, Arizona State Univ.

(United States); E. K. P. Chong, Colorado State Univ. (United States)

8857 OK Efficient multiple emitter localization for fully decentralized large-scale/low-cost multimodal sensor networks [8857-20]

P. J. Haney, BAE Systems (United States); P. D. Fiore, MIT Lincoln Lab. (United States)

$8857 \mathrm{OL}$ Multiple target tracking from images using the maximum likelihood HPMHT [8857-21]

P. Willett, B. Balasingam, Univ. of Connecticut (United States); D. Dunham, T. Ogle,

Vectraxx, Inc. (United States)

SIGNAL SIMULATION PROCESSING

8857 OM Comparison of measured and simulated IR signals from a scaled model ship [8857-23]

D.-G. Kim, K.-I. Han, J.-H. Choi, T.-K. Kim, Chung-Ang Univ. (Korea, Republic of)

Author Index

iv 


\section{Conference Committee}

Program Track Chair

Khan M. Iftekharuddin, Old Dominion University (United States)

Conference Chair

Oliver E. Drummond, Consulting Engineer (United States)

Conference Cochair

Richard D. Teichgraeber, Consulting Engineer (United States)

Conference Program Committee

Liyi Dai, U.S. Army Research Office (United States)

Darren K. Emge, U.S. Army Edgewood Chemical Biological Center (United States)

Denise E. Jones, U.S. Army Space and Missile Defense Command (United States)

Rabinder N. Madan, George Washington University (United States)

Karla K. Spriestersbach, Missile Defense Agency (United States)

Steven W. Waugh, Defense Threat Reduction Agency (United States)

Session Chairs

1 Signal Processing

Lawrence E. Hoff, Hoff Engineering (United States)

Richard D. Teichgraeber, Consulting Engineer (United States)

2 Target Tracking

Richard D. Teichgraeber, Consulting Engineer (United States)

Lawrence E. Hoff, Hoff Engineering (United States)

3 Signal and Data Processing

Larry B. Stotts, Stotts Consulting, LLC (United States)

Richard D. Teichgraeber, Consulting Engineer (United States)

4 Signal Simulation Processing

Richard D. Teichgraeber, Consulting Engineer (United States)

Session Workshop Chair

W1 Workshop: Signal and Data Processing

Richard D. Teichgraeber, Consulting Engineer (United States) 


\section{Introduction}

This was the $25^{\text {th }}$ in a series of SPIE conferences to focus on signal and data processing of small targets. Most SPIE conferences are concerned with processing large targets, namely, targets large enough for traditional automatic (or assisted) target recognition (ATR) with a single frame of data. A 2-D target large enough for ATR is typically larger than 100 resolution elements, for example, larger than 10 by 10 pixels. In contrast, this conference series introduced a different thrust for SPIE in 1989: processing targets smaller than 100 pixels.

This year the conference was held in San Diego after being held in Baltimore the prior year. In the future, these conferences are expected to be located in Baltimore in the spring on even years and continue to be in San Diego in the summer on odd years. The proceedings of the prior conferences in this series in 1989 through 2012 are SPIE Volumes 1096, 1305, 1481, 1698, 1954, 2235, 2561, 2759 , $3163,3373,3809,4048,4473,4728,5204,5428,5913,6236,6699,6969,7445,7698$, 8137, and 8393. A compact disk of all the papers in this series from 1989 through 2000 is available from SPIE; it is Volume 20, which is a two-disk set.

The various types of processing tasks with sensor-derived data of targets can be broadly categorized into four generic classes, as follows:

- Sensor tracking of a single (bright) target

- Image and data processing of large targets

- Signal and data processing of medium sized targets

- Signal and data processing of small targets.

Note that the size indicated in this list is in terms of the number of resolution elements or pixels. The motivation for categorizing the processing of sensor data this way is because most of the appropriate algorithms for each of these problems differ substantially from that of the others. This conference concentrates on small targets that include:

- Point source objects

- Small-extended objects

- Clusters of point source and small-extended objects or threat clouds, such as Chem/Bio threats.

The size of a typical point source target in the field of view is from less than one to about 20 pixels (resolution elements) wide, depending on the sensor design. Although the processing of point targets with data from a single sensor has been 
studied extensively, there are still many interesting challenges in this field. In contrast, the state of the art of sensor data fusion and for processing small extended-objects, clusters, and Chem/Bio clouds is far less mature, but interest is growing. The topic of Chem/Bio has been added because the methods for tracking clusters of objects and tracking of small extended-objects may be applicable with modification. Similarly, the topic of processing for defense against cyber threats has been added because the processing methods developed for target tracking may be helpful.

Small targets that are not point source objects include dismounts, small-extended objects, and unresolved closely spaced objects, sometimes called clumps. While these small targets provide little detailed information useful for ATR, they do exhibit some shape and size information that might be useful in tracking. In addition, an extended object may at times be partially or fully obscured or may obscure rather than add to the background. The apparent size and shape of a target can differ from sensor-to-sensor and over time; this may have to be taken into account. Similarly, cluster and Chem/Bio processing offers significant advantages and unique challenges since they can change in size, shape, and orientation as well as motion.

New or improved sensors, increasingly demanding system requirements, efficacious countermeasures, severe operating environments, processor hardware limitations, new innovative processing methods, and challenging threat scenarios, drive current algorithm development. Of special interest is the ability to track low observables or in a moderate to dense population of threshold exceedances caused by clutter, false signals, or targets that are close or crossing along with the limitation in sensor resolution.

Note that the process of algorithm development is emphasized here because Monte Carlo simulations are needed to obtain functional performance of tracking with confidence. Tracking functional performance is not amenable to mathematical analysis because it depends on random variables from both continuous sample space and discrete sample space. This property makes algorithm design, performance evaluation, and the entire algorithm development process complex and challenging. No surprise that performance results can initially appear counter intuitive.

There is an increasing need for improvements in "algorithm efficiency," i.e., improved performance relative to the processor and communication resources required. A major trade in selecting algorithms for processing small targets is performance versus required processor and communications capacity. Also needed are accurate evaluations and predictions of required resources and functional performance under realistic conditions. Major improvements are needed in: multiple spectral signal processing, multiple target tracking, network centric sensor data fusion, multiple frame data association, multiple frame signal 
processing (such as track-before-detect), effective management of sensors, communications, and processor resources, MHT methods use in cyber domain, target classification/typing, processing of features and attributes, efficient signal processing and tracking of Bio/Chem clouds, adaptive tracking, and the interaction between signal processing and tracking. Many of these issues are highlighted in Figure 1. In addition, there is a need for an indication of track quality and related information in the tracker output to the users and functions that depend on the tracker data to facilitate the improvement of their performance.

The term fuse-before-detect in Figure 1 refers to the combining (fusing) of raw data from multiple sensors before finalizing detection at the signal processing level. I coined this term in recognition of the increased interest in improving performance by fusing sensor data early in the processing chain. Note also in Figure 1 the possible use of track data at the signal processing level. There is a growing recognition of the importance of using all available information in every stage of the processing and hence the use of feedback.

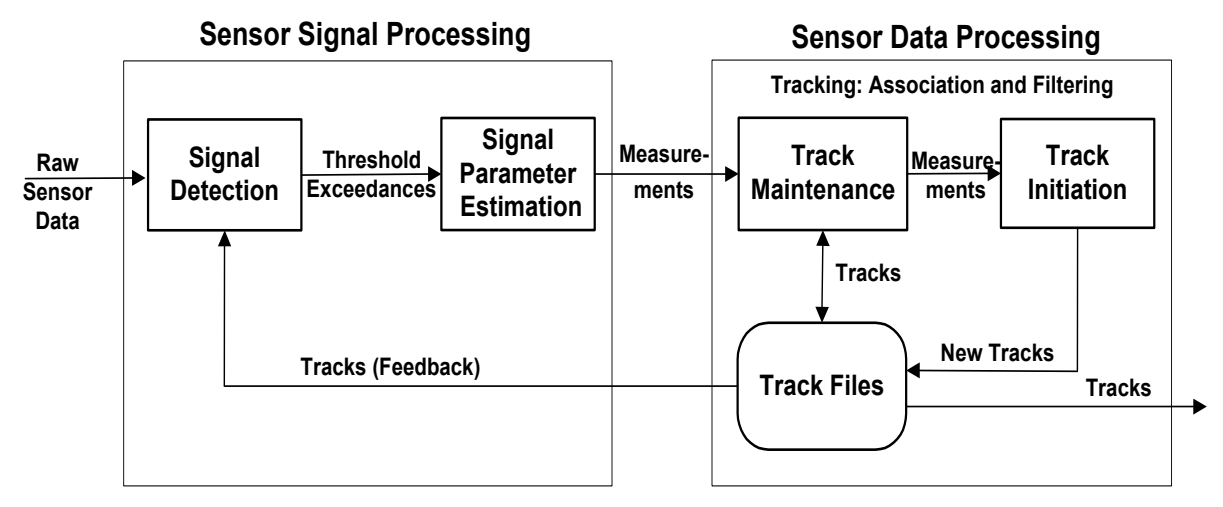

- Single-Frame Signal Processing

- Multiple-Frame Signal Processing

- Fuse Before Detect
- Single-Frame Association

- Multiple-Frame Association

- Multiple-Sensor Processing

Figure 1. Sensor Signal and Data Processing

This conference series has provided a forum to address these issues through discussion of algorithms and simulations for digital signal processing, target tracking, and sensor data fusion, i.e., the functions of data association (correlation) and filtering, including related data processing, such as system resource management, and target classification/typing, all under challenging conditions. Of the three half-day sessions this year, one addressed signal-level 
processing, one addressed target tracking and related functions, and one addressed signal and data processing including network wide processing. The distinction between the two stages of single sensor-level processing is shown in Figure 1.

These proceedings papers contain a wealth of information that address the issues critical to practical processing under the challenging conditions outlined above. For example, important advances were presented in: filter methods to accommodate non-linearities, alternative data association approaches, improved distributed sensor data fusion, processing data of dismounts, high fidelity signal simulation methods, multiple sensor resource management, and cyber network intrusion detection. These techniques and others presented are strong candidates to contribute to achieving high performance target tracking and sensor data fusion plus related processing of low observables or in an environment of moderately dense detections and with abruptly maneuvering targets. These and other innovative yet practical techniques were presented that contribute to improving algorithm efficiency for processing small targets.

Many of the experts and organizations that are making the major important advances in practical sensor signal and data processing have contributed to these proceedings. We thank the authors, session chairs, attendees, and SPIE coordinators for making this conference such a success. They have taken part in enthusiastic discussions that generated better understanding for the application of the techniques presented and have stimulated thoughts for further improvements. Informal discussions during the coffee breaks and the poster session were especially productive, as usual. With these proceedings, the authors have extended the state of the art of analysis, algorithms, and simulations for the use of data from one or more sensors used in signal and data processing of small targets and related processing.

Oliver E. Drummond, Ph.D., P.E. Consulting Engineer Phone: $310-838-5300$

E-Mail: Drummond@Att.Net Web site: http://ODrummond.com 


\title{
Workshop Topic: \\ Signal and Data Processing
}

\author{
Presentation Title: \\ Conference Overview \\ This Series of Conferences Has \\ Added A Daytime Workshop.
}

The conference proceedings and the SPIE Digital Library will use a copy of each author's PowerPoint file instead of a manuscript. See slides 8 and 9 of the presentation that follows for more details about these Workshops 


\title{
SPIE Conference Overview
}

\section{Signal and Data Processing \\ Of Small Targets 2013}

\author{
28 August 2013
}

Oliver E. Drummond, Ph.D., P.E.

Consulting Engineer

310-838-5300

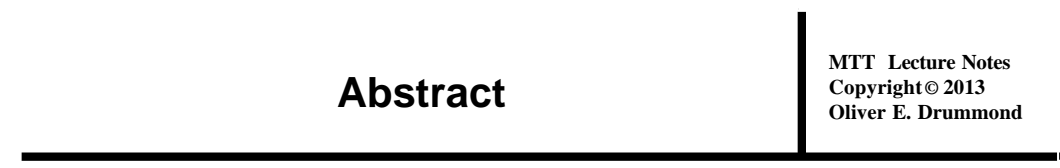

This conference overview addresses the types of targets and the major characteristics of the data encountered in processing sensor data for tracking targets.

The presentation summarizes why tracking these targets make the processing of this data so complex and challenging. The discussion includes a view of the algorithm state of the art, the current drivers in algorithm development, and the critical open issues.

Future direction of this series of conferences is discussed and audience suggestions are invited.

Sp13ConfOvrVw4.Ppt 2 


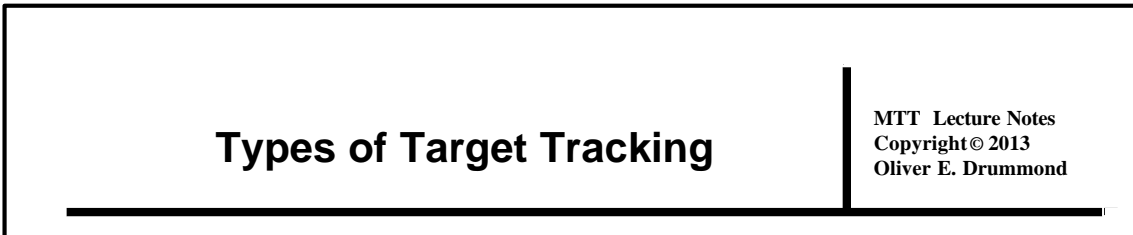

- Sensor Tracking A Single Target

Typically "Closed Loop Tracking" Drives Target Detection To Center Of Field Of View

- Tracking Large Targets

Image Processing Or Image Understanding Permit Identification Of Components Of Target

- Tracking Medium Sized Targets

Correlation Or Ellipsoid Tracker Takes Extent Into Account

- Tracking Small Targets

Isolated and Multiple Target Tracking Methods Handle Ambiguities

Caused By Closely-Spaced Detections

\section{Target Size Refers To Number Of Resolution Elements}

(Pixels) In Target Extent

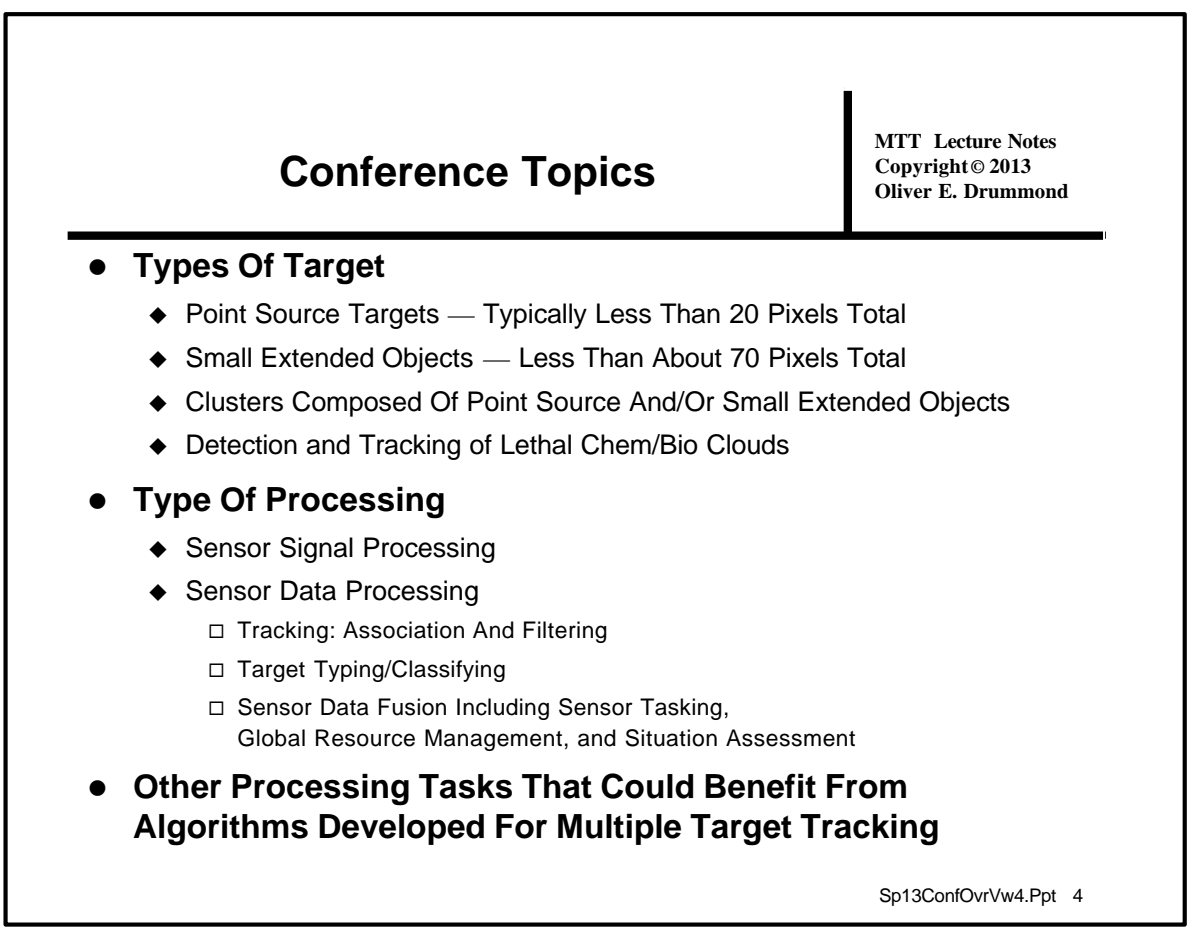




\section{Algorithm Development Drivers

- New or Improved Sensors

- Demanding System Requirements

- Processor Hardware Limitations

- Severe Operating Conditions

- Challenging Threat Scenarios

- New Innovative Processing Methods

\section{Signal and Data Processing мTा Lecture Notes \\ Copyright $\odot 2013$ \\ Oliver E. Drummond}

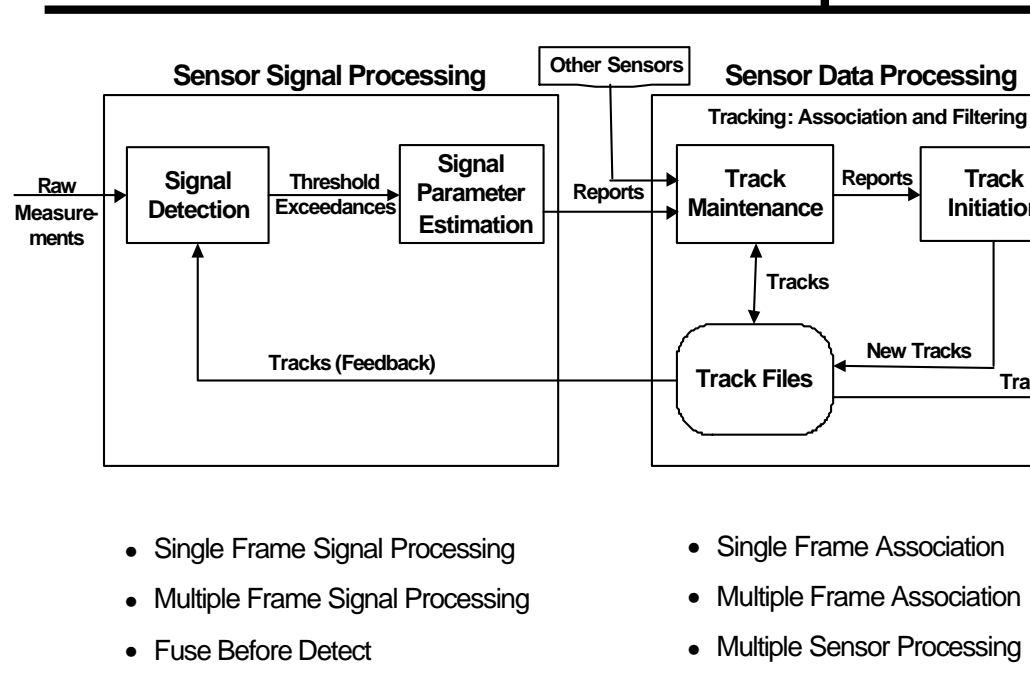




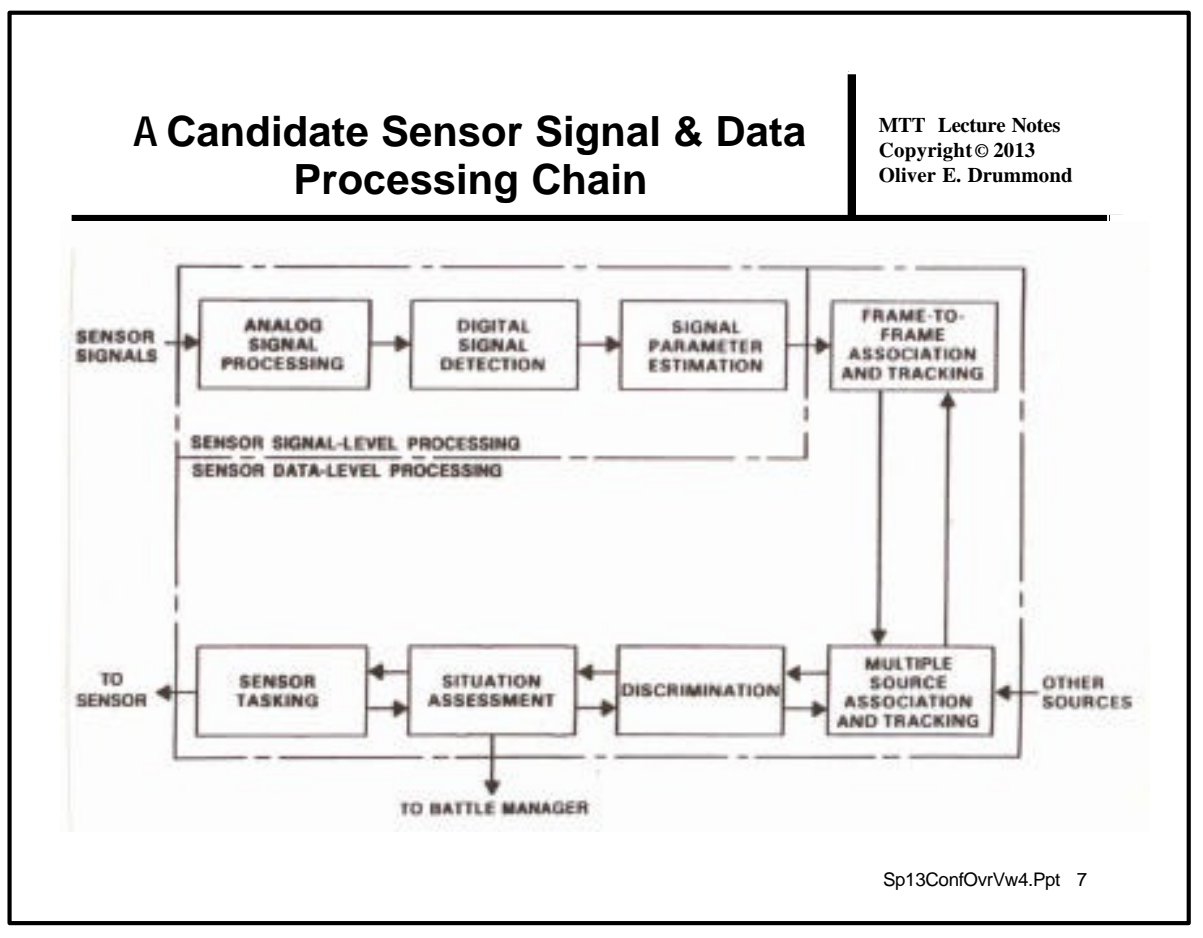

This Series of Conferences Has

MTT Lecture Notes

Copyright $\odot 2013$ Added A Daytime Workshop

- This Workshop Is Similar to a Typical Session of This Conference Except:

- The conference proceedings and the SPIE Digital Library will use a copy of each author's PowerPoint file instead of a manuscript.

- The Workshop authors retain their copyright.

- Workshop is Intended for an Author:

- Whose project has produced significant partial results that should be presented but urgency of the project makes preparing a manuscript now impractical and/or

- Who can easily modify an existing PowerPoint file for the conference and

- Who will present orally as scheduled or ensure that a colleague will.

- All Workshop PowerPoint Files Will be Included in the Front Matter of the Proceedings and Thus in the SPIE Digital Library With Free Access 


\section{More on the Workshop Presentations \\ - Submission of Abstracts to Call-for-Papers \\ - Topics appropriate for Workshop identical to conference regular session. \\ - For Abstract \{only\} add "\{WORKSHOP\}" to beginning of presentation "Title". \\ - For Author Preferred Presentation Type indicate "Oral Presentation." \\ - Workshop is limited to at most 8 presentation chosen by organizers}

\section{- Conference Proceedings and SPIE Digital Library Information}

- PowerPoint (or similar) files will be collected and included in the Front Matter of the conference proceedings and hence included in the SPIE Digital Library with Free Access.

- Submitted PowerPoint (or similar) file is limited to from 6 to12 sheets with one or two slides per page (6 to 24 ) slides.

- First or second slide of the PowerPoint file is to include a copy of the text of the Abstract.

- While authors retain their copyright, SPIE must have the right to include a copy of the submitted PowerPoint in the Conference Proceedings and in the SPIE Digital Library.

\section{Some Critical Issues}

MTT Lecture Notes

Copyright $\odot 2013$

Oliver E. Drummond

- Low Observables and Limited Sensor Resolution

- Dense Environment - Targets, Clutter, False Signals

- Target Maneuvers and Non-linearities

- Counter Measures

- Sensor Data Fusion - Biases, Model Errors, Diverse Sensors

- Accurate Evaluations And Prediction Of:

- Functional Performance

- Required Resources

- Efficient Algorithms That Accommodate:

- Data Association and Filtering

- Multiple Maneuver Models

- Unresolved Closely Spaced Objects

- Multiple Disparate Sensors and Advanced Fusion Functions

- Adaptive Tracking and Failure/Damage Identification and Mitigation 


\section{Multiple Target Tracking Algorithm Status}

- Limitations Of Existing Concepts And Algorithms

- Requires New or Excessive Resources Or

- Unacceptable Tracking Functional Performance Or

- Concepts Identified (Some Radically New) But Not Fully Developed and Performance Not Adequately Evaluated

- Limited Progress Due To:

- Very Complex Problems such as Data Association

- Few Commercial Applications

- Classical Covariance Error Analysis Not Applicable - Monte Carlo Simulations Needed

- Uncertainty of Which Target a Track Is Following Must Be Addressed

- Complex Simulation Beyond Scope Of Normal Academic Research

- Limited Algorithm Design, Development And Evaluation Funding

- Shortage Of Detailed Documentation On Algorithm Development

\section{On The State-of-the-Art Of Tracking мтт Lecture Notes (A Personal Opinion)

- The State-of-the-Art of Tracking With Data From a Single Sensor Under Challenging Conditions Has Improved Greatly in Recent Years Relative to What Is Achievable, but With Some Exceptions.

- Current Multiple Target Processing Methods Do Not Handle the Following Conditions Very Well:

- Advanced sensor data fusion and attribute/feature processing

- Unresolved closely spaced objects or multipath.

- Target splits; track splits and merges.

- Extended objects, especially those that cause multiple detections.

- Dense targets and clutter but small frames, i.e., with few measurements in each frame (possibly overlapping).

- Frames with multiple measurements for the same target.

- Accommodating mathematical model errors and errors in estimates of sensor/target characteristics, possibly non-stationary. 


\section{Some Observations On Target Tracking (1 of 2)}

- Tracking Small Targets Involves Random Variables from Both Discrete and Continuous Sample Space, e.g., Measurement Errors and Assignment Errors:

- Because of the resulting complex nature of the estimation errors, multiple target-tracking performance evaluation and prediction are not amenable to analysis.

- A high fidelity Monte Carlo simulation plus field testing are a necessary part of most tracking algorithm development efforts.

- Some simulation results appear initially to be counterintuitive.

- Algorithm development of the trackers for a system is typically an experimental and recursive process and a long lead task.

- Tracking exhibits properties significantly different from signal processing; in addition to Type 1 and Type 2 errors, tracking exhibits Type 3 errors, that are a combination of both missed and false tracks.

- Different Design Criteria Lead to Different Optimal Solutions.

\section{Some Observations On Target Tracking (2 of 2) \\ MTT Lecture Notes \\ Copyright $\odot 2013$ \\ Oliver E. Drummond}

- By Comparison, for Linear Gaussian Filtering Problems (Without Need of Association Processing) the Kalman Filter Is Optimal For a Wide Variety of Optimization Criteria

- Because Optimal Tracking Performance Methods Are Too Complex to Be Practical, Constrained Optimal or Suboptimal (Ad Hoc) Algorithms Are Typically Devised That Take Advantage of the Particular Targets, Sensors, and Related Conditions of the System for Which the Tracker Is Designed.

- In algorithm development, the major trade is between tracking performance versus cost, processor loading, and communications loading, if applicable.

- Note that the \{Kalman\} filter equations are not very difficult to implement; it is the selection of the type of filter, structure of the mathematical model, and its parameter values used to design the filter that require extensive knowledge and experience. The data association function is similar. 

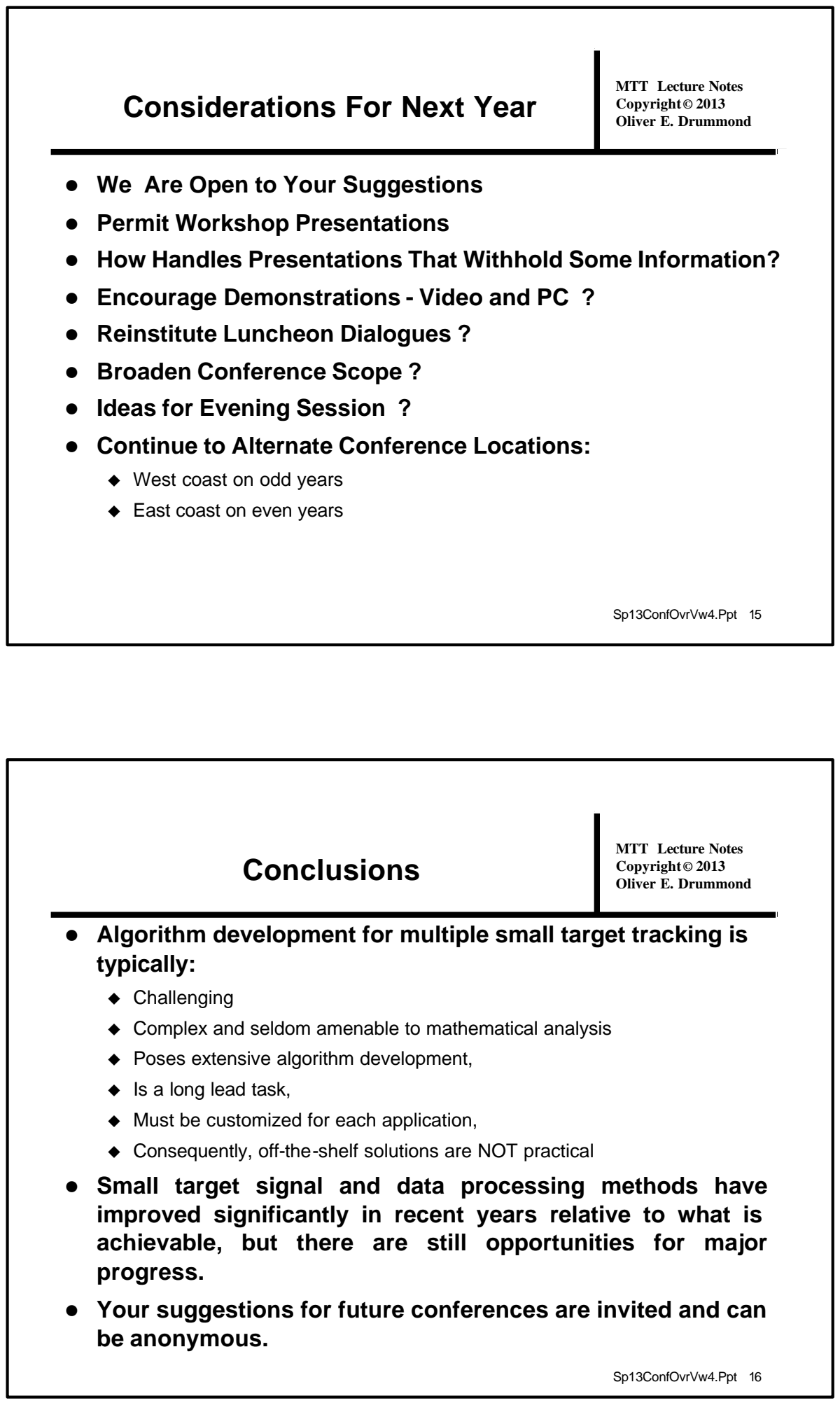